\title{
Using NDVI dynamics as an indicator of native vegetation management in a heterogeneous and highly fragmented landscape
}

\author{
D. Turner $^{\text {a }}$, K. Clarke ${ }^{\text {a }}$, M. Lewis ${ }^{\text {a }}$ and B. Ostendorf ${ }^{\text {a }}$ \\ ${ }^{a}$ School of Earth and Environmental Sciences, The University of Adelaide, Adelaide, 5005 \\ Email:dorothy.turner@adelaide.edu.au
}

\begin{abstract}
Monitoring change and assessing the impact of natural resource management policies is an important task of regional governments. Remote sensing is routinely used to assess vegetation cover. However, spectral indices record variations in vegetation cover and photosynthetic status, and hence vary substantially with weather. Hence observed changes may largely be due to spatio-temporal differences in climatic conditions rather than management. Monitoring small changes in vegetation cover and extent within a large region requires detecting a small signal in a very noisy environment.

The aim of this paper is to assess the detectability of revegetation sites in satellite imagery. We use an indextrends approach, developed and applied to Landsat imagery of the Adelaide and Mount Lofty Ranges (AMLR) Natural Resources Management (NRM) region at $30 \mathrm{~m}$ resolution. Eleven Landsat images (four Landsat-7 ETM+ and seven Landsat-5 TM images) were chosen for analysis, one each from January or February from 2000 to 2010 inclusive. The Normalized Difference Vegetation Index (NDVI) was calculated for each image. During these summer months the contrast in NDVI between dry pasture and weedy grasses and green perennial shrubs and trees can best be detected: most of the revegetation comprises these perennial indigenous species.

We analysed the trends in NDVI, using a linear regression to evaluate the slope of NDVI in the period 20002010. The 10 year trend analysis shows potential to detect changes at the scale of the entire AMLR NRM area of almost a million hectares. Comparison of Landsat NDVI trends with known revegetation patches showed that these increases are not detectable after one year, but both native revegetation and dense forestry plantations were demonstrated to be detectable within 5 years of planting. Revegetation in small linear sections (e.g. along creeks or roadsides) remains obscured.
\end{abstract}

Keywords: Trend analysis, revegetation, modelling, linear regression 


\section{INTRODUCTION}

Native vegetation is vital for the health and prosperity of South Australia's ecosystems, communities and natural resource-based industries. They provide essential habitat for native animal species and help to protect land and water against problems like erosion, salinity and climate change. Over-clearance and degradation of native vegetation in South Australia has been identified as a major concern for many years. Less than $30 \%$ of native vegetation remains in the agricultural areas, with some regions below $10 \%$, while many plants are considered to be threatened (DEWNR, 2012). Broad scale clearance is now strictly controlled through the Native Vegetation Act 2002, and efforts are being made to replace some of what has been cleared to preserve and improve biodiversity.

The Adelaide and Mount Lofty Ranges (AMLR) Natural Resources Management (NRM) Board wish to map and monitor native revegetation in their region. Such a monitoring program must be robust and able to show trends. Some plantings comprise long narrow strips of vegetation that follow roads and fence lines, while others may cover many hectares. Similarly the variety and diversity of plants can vary substantially with mixed plantings of grasses, shrubs and trees, that attempt to emulate remnant vegetation, through to large scale plantations of single species of bushes or trees (Lewis and Summers, 2009). As changes in vegetation occur over extended time frames, appropriately long-term field monitoring would be extremely costly, time consuming, limited in spatial extent, and subject to human error. Conversely, remotely sensed imagery can be an effective tool for regularly repeating surveys of vegetation cover over large areas, with extensively available data at relatively low cost.

The Normalised Difference Vegetation Index (NDVI), also referred to as a greenness index, is a quantitative measure of vegetation vigour, with a range of -1 to +1 (Tucker, 1979). It is based on the properties of photosynthetic structures, which strongly absorb radiation in the red wavelengths of the spectrum and reflect radiation in the infrared wavelengths. NDVI is calculated as $(I R-R) /(I R+R)$, where R is the red reflection and IR is the infrared reflection of the surface. This paper outlines a preliminary scoping project carried out to evaluate the potential of using NDVI for the mapping and monitoring of revegetation projects across the AMLR NRM region. It has been conducted as a lead-in to more comprehensive pilot studies into the potential of remote sensing to better understand the extent, quality and success of revegetation programs carried out in the region.

\section{PROJECT AREA}

The Adelaide and Mount Lofty Ranges (AMLR) Natural Resources Management (NRM) Board's region covers nearly a million hectares, just over half of which is land extending from the Barossa Valley to the Fleurieu Peninsula. It follows the ridge of the western Mount Lofty Ranges and takes in metropolitan Adelaide and the Adelaide Plains. The majority of the AMLR NRM region is included in Landsat Thematic Mapper scenes (images) from Path 97 and Row 84 (Figure 1).

The region supports a mosaic of bushland remnants, farming land, urban development, rolling hills and plains, diverse marine environments and more than $200 \mathrm{~km}$ of spectacular beaches and coastline, creating the most complex landscape in the State. The population and landscapes in the region support diverse industries and makes a significant contribution to the State's economy.

The natural resources of the AMLR NRM region are rich and diverse, with many species unique to this region. It is home to half of the State's species of native plants and three-quarters of its native birds. However, since European settlement, the native vegetation of the region has been subjected to broad-scale clearance and disturbance, particularly in the more fertile areas. This preferential clearance has seen a dramatic decline in formerly dominant grassy ecosystems. Today, approximately $14 \%$ of the pre-European native vegetation cover remains, of which only $29 \%$ is protected under dedicated conservation tenure (AMLR NRM Board, 2008).

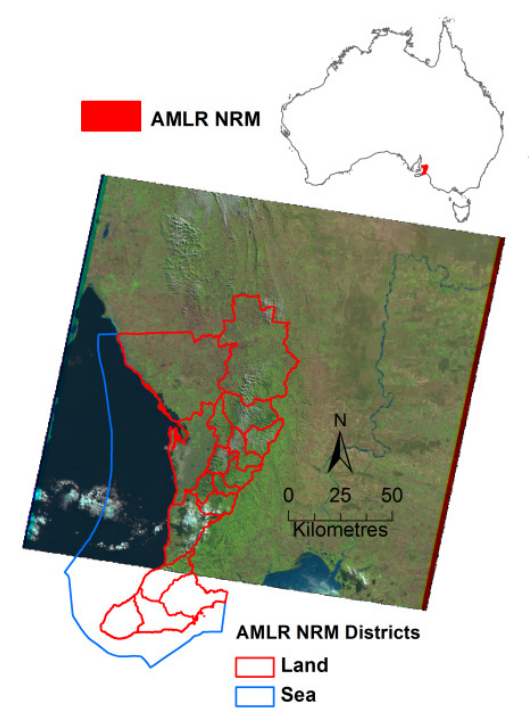

Figure 1. Landsat TM scene (Path 97, Row 84) and AMLR NRM Board boundaries. 


\section{DATA ACQUISITION}

The AMLR NRM Board provided shapefile data on revegetation for the Land Management Program for the 2008/09, 2009/10 and 2010/11 financial years (581 patches/polygons).

Landuse was extracted from the Department of Environment and Natural Resources (DENR) 'Landuse2003-GeoGDA94' spatial database.

We acquired the complete temporal coverage (18 February 2000 to 18 December 2011) for the MODIS satellite Normalised Difference Vegetation Index (NDVI) product for the region. This is a cloud-free composite product measuring vegetation greenness, available at $250 \mathrm{~m}$ resolution once every 16 days (a total of 272 images).

Eleven Landsat Path 97, Row 84 satellite images (30 $\mathrm{m}$ spatial resolution), one each from January or February from 2000 to 2010 inclusive, with the least cloud cover, were downloaded free from the U.S. Geological Survey (USGS) Earth Resources Observation and Science (EROS) Centre. Radiometric calibration of all images was undertaken, based on Chander et al. (2009).

Three Vexcel UltraCamd aerial photography datasets were supplied from DENR (January 2008, November 2010 and January 2011). While none of the 3 UltraCamd datasets are complete coverages of the AMLR NRM region, each covered a large proportion of it, at either $35 \mathrm{~cm}$ or $50 \mathrm{~cm}$ resolution.

\section{DATA ANALYSIS}

\subsection{Revegetation patch size analysis}

Initially, an analysis of the 581 revegetation patches was carried out to determine the minimum patch size required for detection in Landsat imagery (30*30 metre resolution).

\subsection{MODIS temporal NDVI profiles}

The mean NDVI for each land use in the AMLR NRM region was extracted from each of the 272 MODIS images via the Zonal Statistics processing tool in the ArcGIS software. This data was used to create temporal MODIS NDVI profiles for each of these land uses from 2000 to 2011 showing general variation of greenness over 16-day intervals, which highlights seasonal differences between different land uses.

\subsection{Landsat temporal NDVI profiles}

The NDVI was also calculated for each of the 11 Landsat scenes, one each from January or February (where the difference in NDVI between grasses and shrubs/trees can best be detected) from 2000 to 2010 inclusive. Using Zonal Statistics, mean NDVI values were extracted from each image and time-series plots created to show variation in greenness from one summer to another for:

- the AMLR NRM region (excluding the sea)

- $\quad$ each of the revegetation patches mapped for 2008-09, plus a buffer of 30 metres around each of the mapped revegetation patches for 2008-09

- two other areas known to have been revegetated over 5 years ago

\subsection{Landsat NDVI change detection}

Image-differences (subtracting the values of one image from another) can be used to quantify changes for the entire study area between any two periods. This method compares values of corresponding pixels in the two images, to determine which values are different, which indicates some change in ground features over the intervening time. Raster subtraction was performed between the 2005 and 2010 Landsat NDVI images and the results classified to highlight the degree of change more clearly.

\subsection{Landsat NDVI trend analysis}

We used a linear regression to evaluate the slope of NDVI in the period 2000-2010. A linear model (NDVI $\sim 1+$ time) was evaluated for all individual pixel locations within the study area. The most important advantage of using a statistical model, compared with simple change detection, is the ability to assess statistical significance of changes in NDVI. The p-value of the regression model allows masking out all locations with non-significant trends. The t-value of the regression equation is the slope divided by the standard error of the slope, which is a measure of the magnitude of change and the precision of the regression coefficient.

\subsection{Aerial imagery change detection}

Finally, areas of known revegetation from the AMLR NRM Board's database were visually examined to determine how well areas of revegetation could be identified in the aerial imagery and at what time scale.

\section{RESULTS}

\subsection{Revegetation patch size analysis}

The 581 mapped revegetation polygons range in area from 0.008533 hectares $(23 * 3.5 \mathrm{~m})$ to just 
over 32 hectares $(1,000 * 320 \mathrm{~m})$, totalling almost 1,000 hectares. Patch sizes of 1 hectare equate to approximately 11 Landsat $(30 * 30 \mathrm{~m})$ pixels. It is reasonable to expect that patches of this size will be detectable in the Landsat imagery. However, smaller patches may not be detectable as the majority of these patches are long and thin, with many less than one pixel in width. Fortunately, these smaller patches account for only $12.7 \%$ of patches and less than $0.5 \%$ of the revegetated area mapped.

\subsection{MODIS temporal NDVI profiles}

For each image date, the mean MODIS NDVI for several major land uses in the AMLR NRM region were extracted. It was expected that the 'National park' temporal NDVI profile would be a reasonable surrogate for healthy native vegetation. These data were graphed to create temporal NDVI profiles for each of these land uses, and to examine whether it was possible to distinguish the major land uses from healthy native vegetation based on their temporal NDVI profiles (Figure 2).

NDVI is measured from -1 to +1 . NDVI values of approximately 0.1 to 0.2 are indicative of exposed soil or rock, or dead vegetation, while growing vegetation produces values between 0.2 , for very sparse or sickly vegetation, and 0.8 for dense and strongly growing vegetation. Water generally has negative values.

Examining Figure $2 \mathrm{~A}$ and $2 \mathrm{~B}$ it can be seen that vegetation growth in all land uses follows a similar predictable seasonal pattern. Vegetation growth is at a minimum in late summer (low NDVI) then increases through autumn to maximum greenness (high NDVI) in mid-late winter before declining to minimum again in the following summer.

Figure 2A presents the temporal NDVI profiles for National park (a surrogate for healthy native vegetation) and Plantation forestry, which have almost identical periodicity, amplitude and magnitude. Therefore, it is unlikely that these two land uses could be distinguished based on their MODIS NDVI temporal profiles alone. In Figure 2B the temporal NDVI profile for National park and the other major AMLR NRM land uses are presented. While these profiles all follow a similar seasonality, the amplitude and magnitude of National park differs from all other land uses. This difference is most pronounced in summer, where National park NDVI rarely drops below $0.60-0.65$ and all other land uses do. Therefore, the land cover of interest, healthy native vegetation, is probably distinguishable from other land covers based on its summer NDVI.

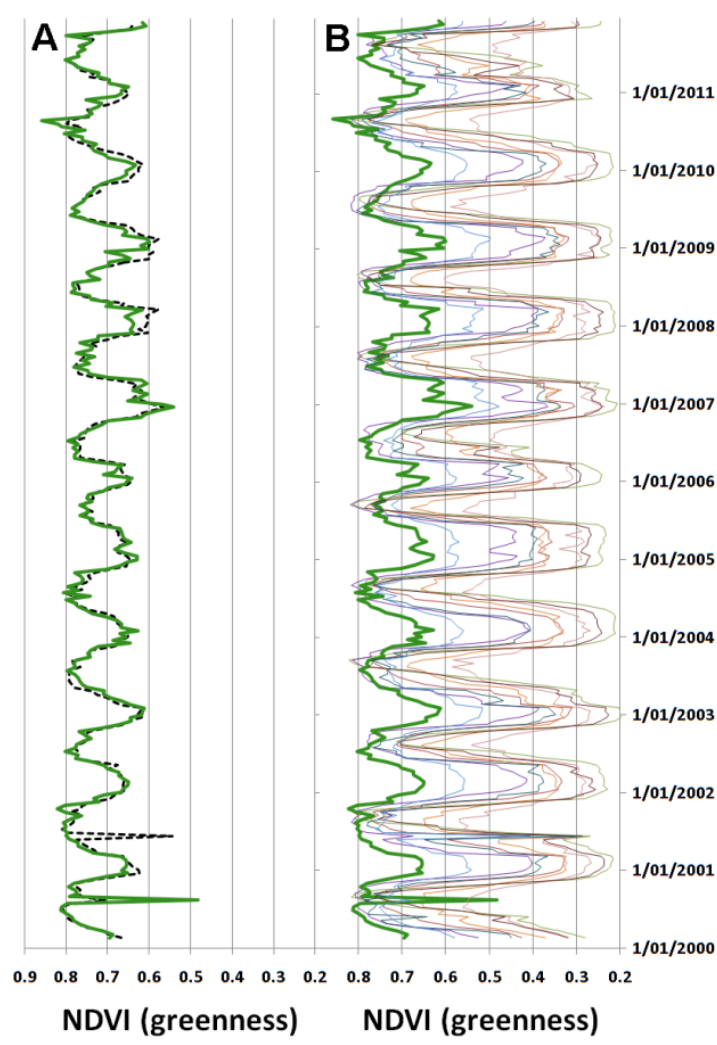

Figure 2. Temporal mean NDVI profiles for major land uses in the AMLR NRM region. Graph A displays the temporal trace for National park (green) and the only highly similar temporal trace, Plantation forestry (black). Graph B displays the temporal trace for National park (green), and temporal traces for a selection land uses in the AMLR region, and demonstrates that summer NDVI in the National park land use is higher than in any other land use in the region

\subsection{Landsat temporal NDVI profiles}

The time-series plot of mean NDVI (measuring 'greenness') of the AMLR NRM land region within the Landsat summer images from 2000 to 2010 showed limited variation between the overall values. The means range from 0.22 to 0.27 with the low values reflecting the fact that these are summer images.

We created a time series plot from 2000 to 2010 for each of the 135 revegetation patches mapped in 2008-09, comparing the mean NDVI of the patch with the mean NDVI of the 30 metre buffer (1 Landsat pixel) around it (see example in Figure 3). Generally the relationships between the patches and their buffers were stable over the 10 years, with slight variations in the values of each (generally less the 0.10 ) reflecting seasonal fluctuations in climate. Following revegetation in 2008-09, very few of the patches show an appreciable difference in NDVI from the historical difference with the buffer area. 
Unfortunately, the earliest revegetation data is for mid 2008 and the latest cloud-free summer Landsat image is from early February 2010, giving only 7 to 19 months between the times of revegetation and the latest Landsat image.

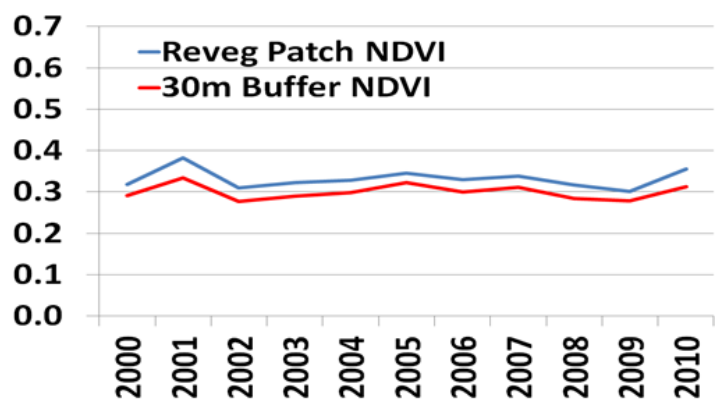

Figure 3. Example of a typical time-series plot comparing mean NDVI from 2000 to 2010

Landsat summer images for an individual revegetation patch from $08-2008$ and its 30 metre buffer (eight and a half years before revegetation and 18 months after).
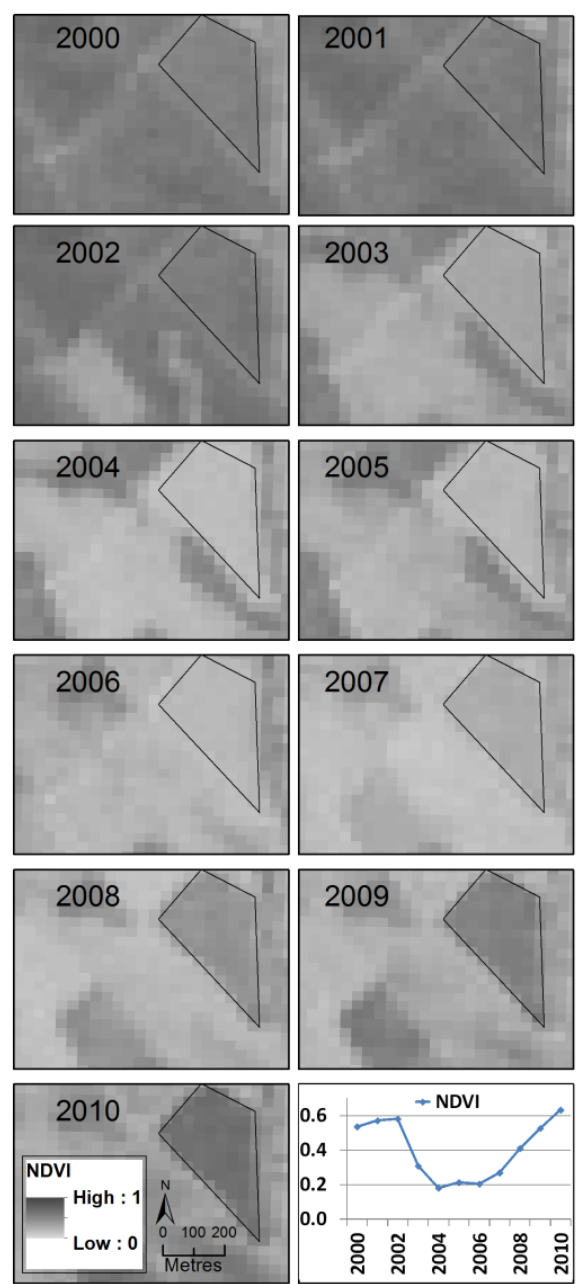

Figure 4. NDVI of plantation forest for Landsat summer images from 2000 to 2010and mean NDVI time-series plot.
A previous report by Lewis and Summers (2009) concluded that it was only reasonable to expect remote sensing to be able to detect new revegetation a few years after planting, after canopies have developed enough to influence overall pixel reflectance. With this in mind, we examined two areas known to have been revegetated over 5 years ago.

The first area of interest was a 7.2 hectare area of plantation forest. Results are presented in Figure 4. We can see it reach maturity in 2002 with a mean NDVI of 0.57 , before being harvested by 2003 . The NDVI drops to around 0.20 for the following three years. There is then a steady increase in NDVI from 2007, reaching a maximum of 0.62 in 2010.

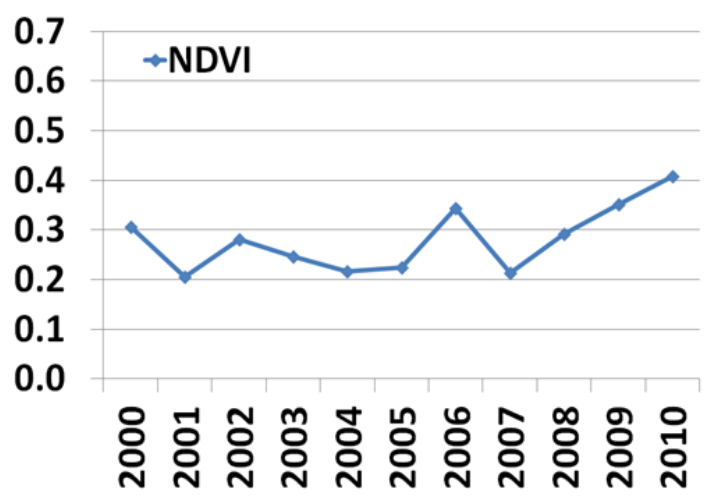

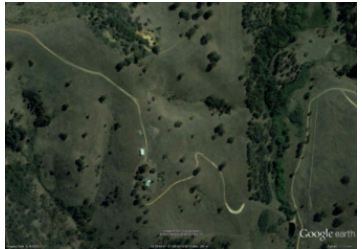

$18-03-2005$

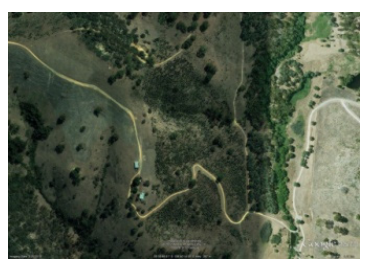

$25-03-2010$

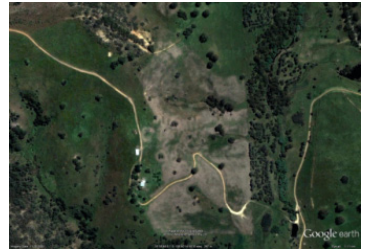

$15-11-2005$

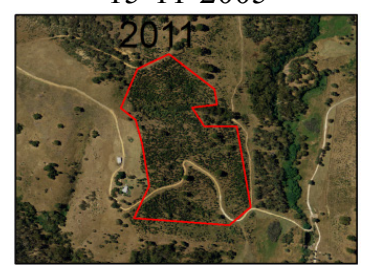

Jan-2011
Figure 5. Mean NDVI of revegetation area for Landsat summer images from 2000 to 2010; and historical imagery (Google Earth 2005 and 2010, Vexcel UltraCamd 2011).

The second area of interest was a 9.8 hectare grassy area approximately. Here, the mean NDVI of the patch fluctuated between 0.2 and 0.3 until 2005, when it was cleared for revegetation, as is clearly visible in the 15-11-2005 image (Figure 5 ). There is a peak in NDVI of 0.34 a few months later in 2006 (possible the growth of weeds and/or 
grass). NDVI falls again to 0.21 in 2007 presumably as the ground is cleared of any weeds in preparation for revegetation. There is then a steady rise in NDVI from 2008 to reach a maximum of 0.41 by 2010 .

\subsection{Landsat NDVI change detection}

Figure 6 shows the differences in NDVI values for the AMLR NRM region of two Landsat images $\left(24^{\text {th }}\right.$ January 2005 and $7^{\text {th }}$ February 2010$)$. The results of this image subtraction (2010 minus 2005) were classified into four groups to most effectively illustrate where cover has increased significantly over this five year period.

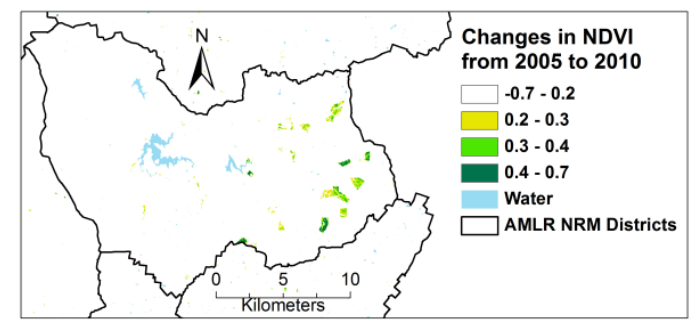

Figure 6. Classification of the change in NDVI from 2005 to 2010 in an AMLR NRM district.

Almost all (99.5\%) of the land area had a decrease in NDVI down to -0.7 or a slight increase of less than 0.2 (shown in white in Figure $6)$. In $0.3 \%$ of the land area the NDVI increased by between 0.2 and 0.3 , while $0.1 \%$ increased by 0.3 to 0.4 . Less than $0.1 \%$ (335 hectares) had an increased in NDVI greater than 0.4 and up to 0.7

\subsection{Landsat NDVI trend analysis}

We used a linear regression to evaluate the slope of NDVI in the period 2000-2010. Figure 7 shows the $t$-value (the slope divided by the standard error of the slope) of the regression equation for the entire study area, which is a measure of the precision of the regression coefficient.

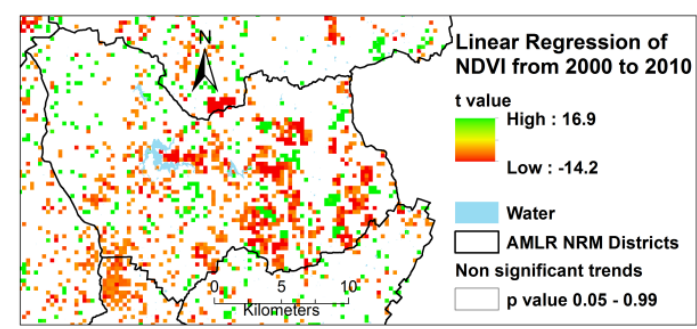

Figure 7. Linear regression of NDVI from 2000 to 2010 in an AMLR NRM district. Nonsignificant trends $(p>0.05)$ are shown as white areas.

All locations with non-significant trends are masked out in white (i.e. the p-value of the regression model between 0.05 and 1.00). High positive $\mathrm{t}$ values are displayed as green (the maximum was almost 17) and low negative $t$ values as red (the minimum was -14).

\subsection{Aerial imagery change detection}

Ultra-high resolution aerial images contain visual information about ecosystem structure. Tree and understory vegetation can be 'seen' and thus potentially mapped. Repeated images thus contain interpretation of how ecosystems have changed over time.

The 2011 Vexcel UltraCamd image in Figure 5 covers an area in the order of $1 \mathrm{~km}^{2}$. At a pixel size of $50 \mathrm{~cm}$ ( 4 pixels per $\mathrm{m}^{2}$ ) this area could be shown on QHD monitor (2,560 x 1,440 pixels) at full resolution. In practical terms this means that, for an area of the size of the AMLR-NRM, about 6000 computer monitor sections would need to be visually interpreted. Using a crude estimate that 10 sections could be interpreted and digitised per hour, this would require 600 hours of work.

Whilst there is some potential for a manual interpretation, the complexity of pattern that needs to be interpreted may be limiting. For example, it can be difficult to correctly identify vegetation conditions, or to distinguish smooth annual herbaceous from homogeneous perennial shrub coverage. The potential to accurately interpret air photos is also limited by the change in surface appearance between seasons. This may be overcome by collecting images during the summer period.

\section{DISCUSSION AND CONCLUSIONS}

One of the guiding targets in the State NRM plan 2012-2017 is to increase the extent (from around $14 \%$ to $30 \%$ cover over the State) and improve the condition of native vegetation. However, current trends in the extent of native vegetation are not well quantified. Trends in vegetation condition are also largely unquantified, but are thought to be declining overall (Government of South Australia, 2012).

The fact that there is currently no compulsory reporting system for private revegetation initiatives makes it very difficult to identify areas that have been revegetated. It is impracticable to assess vegetation changes in the region from the ground because of the size of the region and its fragmented property structure. This mandates broad-scale remote sensing methods to track changes.

Extent and resolution of both the object on the ground, as well as the imagery, are important considerations when choosing remote sensing tools. The majority of vegetation change occurs in 
patches that are sufficiently large to be detected from Landsat imagery at a $30 \mathrm{~m}$ pixel resolution, but not from $250 \mathrm{~m}$ resolution MODIS imagery.

NDVI is an established vegetation index that also proved useful in our study. Change in NDVI over time can be readily visualised and clearly reflect changes in vegetation on the ground. Revegetation shows up as positive changes over a number of consecutive years. Repeated imagery over a large timeframe allows analysis of trends, and the distinction of significant vs. random changes through statistical analysis.

An unsolved issue is how many years are needed to effectively identify change. Choosing the best time periods imposes an undesired level of subjectivity. Analysis with Landsat NDVI of known revegetation patches shows that these changes are not detectable after one year, but both native revegetation and dense forestry plantations were demonstrated to be detectable within 5 years of planting. Results of statistical analyses are also influenced greatly by the time frame chosen.

High resolution aerial photography has some potential for assessing known areas of revegetation. Pattern in the imagery changes dramatically in different seasons and even if we know that an area has changed and even if we can clearly see individual small plants in the image it may be very difficult to identify areas that have changed. The available imagery shows how important it is to acquire imagery in similar seasons and time of day to standardise ephemeral plant biomass and the shadows cast. It currently has limited potential to detect new areas.

A possibility that needs to be explored is the use of MODIS to look at the broader context, then Landsat to detect changes, potentially coupled with manual air photo interpretation to identify conditions on the ground that might have caused the change in the broader-scale imagery (Hyde et al., 2006). This may help in distinguishing native vegetation restoration from blue gum plantations (which can have negative environmental effects through water use) or invasive olives for example.

A number of free operational products from the National Carbon Accounting System - Land Cover Change Project (NCAS-LCCP) may be appropriate for the AMLR NRM region, in particular, 'Forest Cover', 'Land Cover Change' and 'New Forest/Plantation Type' (Furby et al., 2008). The NCAS-LCCP 'National Forest Trend' and 'Sparse Perennial Vegetation Cover' products, currently in development, could also be useful if made available to the public (Lehmann et al., 2013).

\section{ACKNOWLEDGEMENTS}

This work is funded by the AMLR NRM Board.

\section{REFERENCES}

AMLR NRM Board (2008). Creating a sustainable future: An Integrated natural resources management plan for the Adelaide and Mount Lofty Ranges Region. Volume A: State of the Region report. Adelaide and Mount Lofty Ranges Natural Resources Management Board.

Chander, G., Markham, B.L., Helder, D.L. (2009). Summary of current radiometric calibration coefficients for Landsat MSS, TM, ETM+, and EO-1 ALI sensors. Remote Sensing of Environment, 113, 893-903.

DEWNR (2012). Native vegetation. Available at http://www.environment.sa.gov.au/Conservatio n/Native vegetation, Department of Environment, Water and Natural Resources, Government of South Australia.

Furby, S. L., Caccetta, P. A., Wu, X. \& Chia, J. (2008). Continental Scale Land Cover Change Monitoring in Australia using Landsat Imagery. International Earth Conference: Studying, modeling and Sense Making of Planet Earth, 2008b Mytilene, Lesvos, Greece, 2008 .

Government of South Australia (2012). Our Place. Our Future. State Natural Resource Management Plan South Australia 2012 2017, Adelaide.

Hyde, P., Dubayah, R., Walker, W., Blair, J.B., Hofton, M. and Hunsaker, C. (2006). Mapping forest structure for wildlife habitat analysis using multi-sensor (LiDAR, SAR/InSAR, ETM plus, Quickbird) synergy. Remote Sensing of Environment, 102, 63-73.

Lehmann, E. A., Wallace, J. F., Caccetta, P. A., Furby, S. L. \& Zdunic, K. (2013). Forest cover trends from time series Landsat data for the Australian continent. International Journal of Applied Earth Observation and Geoinformation, 21, 453-462.

Lewis, M. and Summers, D. (2009). Potential for the use of remote sensing to map and monitor revegetation in South Australia. Report prepared for the Department of Water, Land, Biodiversity Conservation.

Tucker, C.J. (1979). Red and photographic infrared linear combinations for monitoring vegetation. Remote Sensing of Environment, 8, 127-150. 